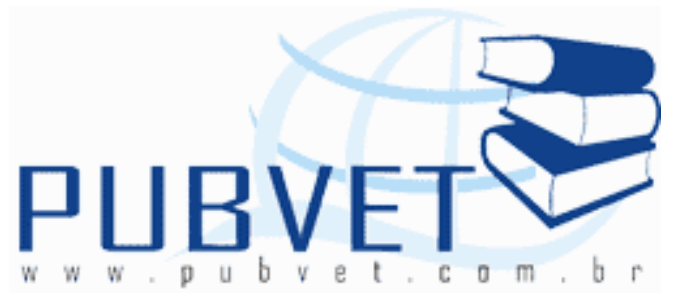

PUBVET, Publicações em Medicina Veterinária e Zootecnia.

\title{
Resíduos da indústria de etanol e de biodiesel na alimentação animal
}

Juliana Klug Nunes ${ }^{1 *}$, Fernando Rutz ${ }^{2}$, Marcos Antonio Anciuti ${ }^{3}$, Fabiane

Pereira Gentilini ${ }^{3}$, Cristiéle Lange Contreira ${ }^{4}$, Liliane Novelini ${ }^{4}$, Verônica Lisboa Santos ${ }^{5}$, Priscila Moraes ${ }^{4}$

${ }^{1}$ D.Sc., Médica Veterinária - Universidade Federal de Pelotas

${ }^{2}$ Prof. Ph.D., Médico Veterinário - Universidade Federal de Pelotas

3 Prof. D.Sc., Médico Veterinário - Instituto Federal Sul rio-grandense Campus Pelotas - CaVG

${ }^{4}$ Engenheira Agrônoma - Universidade Federal de Pelotas

${ }^{5}$ M.Sc., Engenheira Agrônoma - Universidade Federal de Pelotas

*Autor para Correspondência. E-mail: julianaklug@yahoo.com.br

\section{Resumo}

A partir da transformação dos grãos de cereais para a produção de etanol são gerados os resíduos secos e solúveis de destilaria (DDGS) que correspondem a aproximadamente $30 \%$ do cereal empregado. Logo, objetivou-se reunir informações sobre a utilização de DDGS na alimentação animal. Os ingredientes normais a serem substituídos por DDGS são milho, farelo de soja e de trigo. O alto percentual de fibra, a concentração de ácidos graxos insaturados para suínos em terminação, as micotoxinas e os baixos percentuais de aminoácidos e minerais limitam o uso de DDGS na dieta de não ruminantes, sendo aconselhável o emprego de ensaios de avaliação nutricional. A qualidade e a palatabilidade dos DDGS influenciam o 
desempenho produtivo dos animais. A formulação da dieta para suínos contendo DDGS precisa ser baseada em teor de energia líquida $e$ aminoácidos digestíveis; e a inclusão de DDGS pode ser em, pelo menos, $20 \%$. É importante a realização de mais estudos com cães e gatos.

Palavras-chave: cães, DDGS, dieta, gatos, suínos.

\section{Wastes from ethanol and biodiesel in animal feed}

\section{Summary}

From the transformation of cereals for the production of ethanol are generated the residues dried distillers solubles (DDGS) corresponding to approximately $30 \%$ of the cereal used. This study aimed to gather information on the use of DDGS in animal feed. The normal ingredients to be replaced by DDGS are corn, soybean and wheat. The high percentage of fiber, the concentration of unsaturated fatty acids for finishing swine, mycotoxins and the low percentage of amino acids and minerals limit the use of DDGS in diets for non-ruminants, being recommended the use of nutritional assessment tests. The quality and palatability of DDGS influence productive performance of animals. The formulation of diets for swine containing DDGS must be based on energy content and liquid digestible amino acids, and can be DDGS inclusion at least $20 \%$. It is important to conduct more studies with dogs and cats.

Keywords: dogs, DDGS, diet, cats, pigs.

\section{Introdução}

Os Estados Unidos, maior produtor de etanol, utiliza o milho como principal substrato. Já no Canadá e na Europa são o trigo e a cevada os principais cereais utilizados para a produção do etanol. O Brasil, segundo maior produtor mundial de etanol, emprega a cana-de-açúcar como base (VEJA, 2012). 
NUNES, J.K. et al. Resíduos da indústria de etanol e de biodiesel na alimentação animal. PUBVET, Londrina, V. 7, N. 18, Ed. 241, Art. 1593, Setembro, 2013.

A partir da transformação dos grãos de cereais para a produção de etanol são gerados os resíduos secos e solúveis de destilaria (DDGS) que correspondem a aproximadamente $30 \%$ do cereal empregado. Portanto, a tendência do aumento da utilização de fontes energéticas convencionais para a produção do etanol, com consequente decréscimo de grãos para a alimentação animal, principalmente do milho, tornará os DDGS mais disponíveis e como uma alternativa para a alimentação animal (MALLMANN et al., 2009).

Além do processo de moagem a seco para a produção de etanol, a via úmida também pode ser utilizada e é responsável por $18 \%$ da produção de etanol. Do emprego do milho como principal matéria-prima e da via úmida na produção do etanol são resultantes farinha e farelo de glúten de milho, farelo de gérmen de milho e fibra de milho como subprodutos (GODOY et al., 2009).

Os DDGS de milho apresentam proteína de baixa qualidade devido ao baixo conteúdo de lisina, treonina e triptofano e a digestibilidade dos aminoácidos pode ser reduzida durante o processamento e secagem dos grãos de cereais. Para suínos, por exemplo, o coeficiente de digestibilidade verdadeira dos DDGS de milho varia entre 43,9 e 63,0\% (STEIN et al., 2006). Fastinger \& Mahan (2006) empregaram cinco fontes de DDGS de milho com participação aproximada de $60 \%$ nas dietas para suínos com o mesmo peso inicial e identificaram uma variação da digestibilidade ileal aparente da lisina de 24,6 a $52,3 \%$.

A fim de evitar fontes de DDGS com baixa digestibilidade de aminoácidos, é aconselhável o emprego de ensaios de avaliação nutricional dos DDGS antes de acrescentar a dieta, como o NIRS (MALLMANN et al., 2009). Além disso, é importante formular as dietas com base em aminoácidos digestíveis ao ser utilizado acima de 10\% de DDGS na alimentação dos animais (STEIN \& SHURSON, 2009). Stein \& Shurson (2009) recomendam o uso de DDGS com relação lisina:proteína bruta superior a $2,80 \%$. 
A cor do DDGS tem correlação com a digestibilidade de aminoácidos, pois os DDGS com coloração mais escura apresentaram valores menores de digestibilidade (FASTINGER \& MAHAN, 2006). Pedersen et al. (2005) consideram que os parâmetros de cor, brilho e intensidade do amarelo, são indicadores razoáveis para prever o conteúdo de lisina digestível em DDGS. Segundo Fastinger \& Mahan (2006) a lisina é o aminoácido que tem a sua digestibilidade mais afetada, quando a coloração dos DDGS torna-se mais escura.

Os DDGS de milho contém de 10 a $11 \%$ de lipídios (STEIN \& SHURSON, 2009). Em termos de energia, para suínos os valores de energia digestível (ED) e metabolizável (EM) dos DDGS são 3441 e $3032 \mathrm{kcal} / \mathrm{kg}$, respectivamente (NRC, 1998). Entretanto, Pedersen et al. (2007) sugeriram valores médios de $4140 \mathrm{kcal} / \mathrm{kg}$ para ED e $3897 \mathrm{kcal} / \mathrm{kg}$ para EM (valores expressos na matéria seca), ou seja, valores similares aos que determinaram para o milho - ED de $4088 \mathrm{kcal} / \mathrm{kg}$ e EM de $3989 \mathrm{kcal} / \mathrm{kg}$. A variação dos níveis de proteína, de extrato etéreo, cinzas e FAD dos cereais interferem na variação de ED e EM dos DDGS (PEDERSEN et al., 2007).

Com relação ao teor de fibra, pesquisadores analisaram diferentes fontes de DDGS. Stein \& Shurson (2009) obtiveram uma média de 40,1\% para fibra detergente neutra (FDN) enquanto que Pedersen et al. (2007) constataram 27,6\%. Devido ao aumento de FDN e/ou dos níveis de gordura na dieta ocorre redução linear na digestibilidade aparente da gordura (NOBLET \& PEREZ, 1993).

Um aspecto importante na avaliação de DDGS é a sua composição em macro e microelementos. Como os DDGS correspondem a aproximadamente $1 / 3$ do valor total do milho, tendo os outros $2 / 3$ sido transformados em etanol e dióxido de carbono, as concentrações de minerais deveriam ser aproximadamente três vezes àquelas do grão de milho, o que pode tornarse uma limitação no seu uso (RIBEIRO et al., 2010). Entretanto, Batal \& Dale (2003), ao analisarem 12 amostras de DDGS, não encontraram essa proporção esperada, principalmente para sódio, cálcio e enxofre e 
verificaram variações significativas entre as amostras para manganês, ferro, cobre e alumínio. Segundo Godoy et al. (2009) a variação na composição mineral dos DDGS pode ser influenciada pela cultivar, produção e características do solo onde o grão foi cultivado.

A concentração de fósforo nos DDGS é aproximadamente $0,60 \%$ e a digestibilidade aparente total deste mineral é aproximadamente $60 \%$, estes são percentuais superiores aos observados para o milho $(19,3 \%)$ (PEDERSEN et al., 2007). Portanto, ao se incluir DDGS nas dietas a suplementação de uma fonte de fósforo inorgânico pode ser reduzida (STEIN \& SHURSON, 2009).

Também é importante a realização de testes para micotoxinas, quando são utilizados DDGS nas dietas para animais, pois se houver micotoxinas no milho utilizado para a produção de etanol estas permanecerão nos DDGS, pois não são destruídas ou inativadas durante o processo de fermentação. $\mathrm{Na}$ verdade, a concentração de micotoxinas nos DDGS aumentará de duas a três vezes em relação a concentração inicial nos grãos, pois com a remoção do amido, durante a fermentação, todos os componentes não fermentáveis do grão se concentram (STEIN \& SHURSON, 2009).

\section{DDGS na dieta de suínos}

Whitney \& Shurson (2004) conduziram experimentos com a utilização de $0,5,10,15,20$ ou $25 \%$ de DDGS, durante a fase de creche de leitões, a fim de avaliar o desempenho destes animais submetidos ao desmame precoce. Durante os quatro primeiros dias pós-desmame os leitões receberam ração peletizada comercial (fase 1). Após, durante 14 dias, receberam as dietas experimentais da fase 2 e por mais 21 dias da fase 3 . A taxa de crescimento, o peso corporal e a conversão alimentar foram similares entre os tratamentos. Os autores concluíram que até $25 \%$ de DDGS de milho pode ser incluído na dieta da fase 2 de leitões com peso mínimo de $7 \mathrm{~kg}$ e que o mesmo percentual pode ser incluído, após duas 
NUNES, J.K. et al. Resíduos da indústria de etanol e de biodiesel na alimentação animal. PUBVET, Londrina, V. 7, N. 18, Ed. 241, Art. 1593, Setembro, 2013.

semanas de adaptação, na terceira fase da nutrição de suínos na creche, sem que efeitos negativos no desempenho dos animais sejam observados.

Autores demonstraram que fornecer, 10 dias após o desmame, 10\% de DDGS em dietas para leitões (BENZ et al., 2007) e, três semanas após o desmame, 30\% de DDGS (BURKEY et al., 2008), manteve o desempenho produtivo dos suínos. Já ao adicionar 30\% de DDGS de sorgo em dietas de desmame para leitões, Feoli et al., (2008a) observaram efeito negativo sobre o desempenho.

Ao realizar pesquisa com leitões em crescimento, Thacker (2006) verificou que a adição de $0,5,10,15,20$ ou $25 \%$ de DDGS em dietas à base de trigo e farelo de soja resultou em redução linear no ganho de peso e no consumo de ração, sem afetar a eficiência alimentar. Por outro lado, quando o mesmo autor, durante a fase de terminação dos suínos, reduziu a quantidade de DDGS nas dietas à base de trigo e farelo de soja para 0, 3, 6, 9, 12 ou $15 \%$ não observou efeito sobre o desempenho. O pesquisador atribui a diferença observada a formulação das dietas com base no conteúdo de aminoácidos totais.

Em dietas de crescimento-terminação para suínos, o ganho de peso é reduzido e a eficiência alimentar pode ser reduzida (FEOLI et al., 2008a) quando o DDGS é adicionado em $40 \%$ do total da dieta. Os pesquisadores que observaram redução no desempenho dos animais atribuíram o resultado a baixa qualidade do DDGS usado, ou seja, a menor utilização de nutrientes e a redução na palatabilidade do DDGS, pois quando os suínos podem escolher, eles têm preferência pela dieta sem DDGS (HASTAD et al., 2004).

Após incluir $30 \%$ de DDGS de trigo ou de sorgo às dietas de suínos, a relação percentual entre o peso da carcaça eviscerada a quente e o peso corporal foi determinada por Feoli et al. (2008b) que observaram redução nesta relação. Os pesquisadores atribuem a redução dessa relação ao conteúdo relativamente alto de fibra presente no DDGS. O alto teor de fibra nas dietas de suínos em fase de crescimento-terminação reduz a relação 
NUNES, J.K. et al. Resíduos da indústria de etanol e de biodiesel na alimentação animal. PUBVET, Londrina, V. 7, N. 18, Ed. 241, Art. 1593, Setembro, 2013.

entre peso da carcaça eviscerada a quente e o peso corporal (KASS et al., 1980).

Em dietas, para suínos em crescimento e terminação, com níveis similares de lisina, cálcio e fósforo, Whitney et al. (2006) incluíram 0, 10, 20 ou $30 \%$ de DDGS de milho e observaram que os níveis de 20 e $30 \%$ comprometeram o ganho de peso dos animais, e que $30 \%$ piorou a conversão alimentar, comprometeu a profundidade de lombo e a consistência da gordura. Por outro lado, espessura de toucinho e percentagem de carne magra não foi afetada pelos níveis de DDGS estudados.

Os suínos alimentados com 10 ou $20 \%$ de DDGS de milho, na fase de crescimento-terminação, por Widmer et al. (2008) não sofreram diferença na composição da carcaça, na qualidade muscular, na palatabilidade e nem no peso final, mas tiveram redução na consistência da gordura abdominal quando comparados com os suínos que receberam dieta à base de milho e farelo de soja. Ao ser oferecido $20 \%$ de DDGS de milho (BENZ et al., 2010) e $30 \%$ de DDGS de sorgo (FEOLI et al., 2008b). para suínos houve aumento do índice de iodo na gordura abdominal, pois estes DDGS apresentam quantidades relativamente grandes de ácidos graxos insaturados, especialmente de ácido linoleico (C18:2), e como resultado ocorre alteração do grau de saturação da gordura com consequente redução da consistência.

Os trabalhos realizados com a utilização de estratégias nutricionais para reduzir os efeitos negativos da alimentação com DDGS sobre a qualidade da gordura de suínos em crescimento-terminação demonstraram que ao ser incluído 20 ou $40 \%$ de DDGS de milho na dieta de suínos com a adição de $1 \%$ de ácido linoleico conjugado, durante 10 dias que antecederam o abate, diminuiu o índice de iodo na gordura e a proporção n6:n3 (WHITE et al., 2007). Hill et al. (2008) e Bergstrom et al. (2009) observaram, respectivamente, que a retirada ou a redução de 60 para $20 \%$ de DDGS da dieta, nas quatro semanas antes do abate, resultou em carcaça com índice de iodo em torno de 70, índice aceitável. 
NUNES, J.K. et al. Resíduos da indústria de etanol e de biodiesel na alimentação animal. PUBVET, Londrina, V. 7, N. 18, Ed. 241, Art. 1593, Setembro, 2013.

$\mathrm{Xu}$ et al. (2008) avaliaram pelo Teste de Reatividade ao 2Tiobarbiturato (Thiobarbituric Acid Reactive Test, TBAR) a gordura do lombo de suínos alimentados com 30\% de DDGS e armazenados por 1, 14, 21 e 28 dias e não verificaram oxidação da gordura, mesmo que o consumo de DDGS aumente o conteúdo de ácidos graxos insaturados na gordura.

Com relação a coloração subjetiva do lombo suíno, rosa-avermelhada brilhante, Xu et al. (2008) demonstraram que os DDGS (0 a 30\%) na dieta não afetaram esse aspecto e que foi de 3,0 o escore visual médio. Os mesmos pesquisadores também verificaram que a coloração da gordura abdominal aferida com o uso do Minolta $L^{*}, a^{*}$ e b*, a perda por cocção e as características de lombo e bacon não foram influenciadas quando os níveis dietéticos de DDGS aumentaram de 0 para $30 \%$ na dieta de crescimentoterminação de suínos.

Os autores supracitados também realizaram testes de degustação para sabor, maciez, suculência e aceitabilidade do lombo e os resultados foram semelhantes para as amostras. O rendimento de preparo do bacon, o sabor, a crocância e a apreciação foram similares entre os diferentes níveis de DDGS na dieta. Em geral, os resultados dos testes sensoriais mostraram que o uso de dietas contendo até $30 \%$ de DDGS não influenciou o sabor e as características alimentares da carne suína. Um benefício dos DDGS é a redução da produção de escatol no intestino grosso, o que diminui o odor de macho na carcaça (XU et al., 2008).

A coloração do músculo e da gordura se manteve com a inclusão de até $30 \%$ de DDGS na dieta de suínos, este aspecto de qualidade da carcaça de suínos é importante, pois influencia a aparência e atratividade da carne ao consumidor (FASTINGER \& MAHAN, 2006).

Durante dois partos, ao avaliarem o desempenho de matrizes suínas alimentadas, durante a gestação, com dietas que continham 0 ou $50 \%$ de DDGS e durante a lactação com dietas que continham 0 ou $20 \%$ de DDGS, Wilson et al. (2003) observaram que, no primeiro ciclo reprodutivo, a mortalidade pré-desmame foi maior para as fêmeas que receberam $50 \%$ de 
NUNES, J.K. et al. Resíduos da indústria de etanol e de biodiesel na alimentação animal. PUBVET, Londrina, V. 7, N. 18, Ed. 241, Art. 1593, Setembro, 2013.

DDGS na gestação e $20 \%$ de DDGS na lactação. As matrizes alimentadas com DDGS, durante a gestação anterior apresentaram menor intervalo desmama-cio do que aquelas que não receberam DDGS na gestação ou lactação. As fêmeas suínas alimentadas com DDGS, apenas na lactação, apresentaram durante os sete dias iniciais do período de lactação, do primeiro ciclo reprodutivo, menor consumo de ração. Os pesquisadores concluíram que o DDGS pode ser adicionado nas dietas de lactação em até $20 \%$ e que a não inclusão do DDGS na dieta de gestação pode causar redução do consumo de ração pela matriz durante o período imediato ao pós-parto.

Ao alimentarem matrizes suínas em lactação de 19 dias com dietas contendo $0,10,20$ ou 30\% de DDGS, Greiner et al. (2008) não observaram diferenças entre os tratamentos experimentais para consumo de ração, ganho de peso da leitegada e do leitão, mortalidade pré-desmame ou intervalo desmama-cio, porém verificaram aumento linear no ganho de peso da matriz suína e redução linear no intervalo desmama-cio. Song et al. (2007) verificaram que DDGS incluídos na dieta de lactação em 20 ou 30\% não afetou os percentuais de proteína e de gordura do leite e nem a digestibilidade ou a retenção de nitrogênio das matrizes suínas, mas proporcionou redução na concentração de ureia em comparação as fêmeas alimentadas com a ração controle.

O conteúdo de fósforo, cálcio, cobre, zinco, nitrogênio, magnésio, sódio e enxofre na dieta tende a aumentar, assim como a taxa de emissão ( $\mathrm{mg} / \mathrm{min}$ ) de gases - $\mathrm{NH}_{3}, \mathrm{H}_{2} \mathrm{~S}, \mathrm{CO}_{2}, \mathrm{CH}_{4}$ e $\mathrm{N}_{2} \mathrm{O}$ quando há aumento de 0 para $40 \%$ no percentual de DDGS na dieta de suínos em crescimento (SPIEHS et al., 2002). Logo, o aumento do consumo e da excreção de minerais ocorre porque os níveis de micro e macrominerais aumentam com o aumento de DDGS na dieta (SPIEHS et al., 2002). 


\section{Recomendações da inclusão de DDGS nas dietas de suínos}

As recomendações dos níveis de inclusão de DDGS na dieta de suínos (Tabela 1) indicados por Pedersen et al. (2007) assumem uma fonte de boa qualidade, livre de micotoxinas e em dietas formuladas com base no conteúdo de aminoácidos digestíveis e fósforo disponível, a fim de que os resultados desempenho sejam semelhantes aos obtidos com o fornecimento de rações à base de milho e farelo de soja.

Dependendo da qualidade da gordura fornecida a suínos em crescimento-terminação e da manutenção da ração nas 3-4 semanas que antecedem o abate, as dietas com mais de $20 \%$ de DDGS podem reduzir a consistência da gordura abdominal dos suínos. Para as matrizes, acima de $50 \%$ de DDGS podem ser adicionados nas dietas de gestação e $30 \%$ nas dietas de lactação, se a fonte de DDGS for isenta de micotoxinas. Entretanto, pode ser necessário a realização de um período de adaptação quando for realizada a transição de dietas à base de milho e farelo de soja para dietas contendo altas concentrações de DDGS na lactação.

Tabela 1. Recomendação máxima da inclusão de DDGS nas dietas de suínos

\begin{tabular}{lc}
\hline Fase & Máximo na dieta (\%) \\
\hline Creche (mais do que 7kg) & 30 \\
Crescimento-terminação & 30 \\
Marrã & 30 \\
Matriz suína em gestação & 50 \\
Matriz suína em lactação & 30 \\
Cachaço & 50
\end{tabular}

Fonte: PEDERSEN, 2007.

Segundo Stein \& Lange (2007) para cada inclusão de 10\% de DDGS nas dietas de suínos deve ser aumentada a quantidade de lisina sintética em $0,10 \%$, reduzido em $5,70 \%$ a quantidade de milho e em $4,25 \%$ o farelo de 
soja. Devido à maior concentração e digestibilidade do fósforo nos DDGS que na soja, pode-se suprimir, aproximadamente, $0,20 \% \circ$ fosfato monocálcico, tendo que acrescentar carbonato de cálcio para manter a concentração de cálcio adequada (Tabela 2).

Tabela 2. Efeito de incluir 10\% de DDGS nas dietas de suínos

\begin{tabular}{lcc}
\hline Ingredientes, \% & Dieta de gestação & Outras dietas \\
\hline Milho & $\downarrow 7,40$ & $\downarrow 5,70$ \\
Farinha de soja, 48\% & $\downarrow 2,40$ & $\downarrow 4,25$ \\
Fosfato monocálcico & $\downarrow 0,22$ & $\downarrow 0,20$ \\
Lipídios & $\downarrow 0,10$ & $\downarrow 0,05$ \\
L-Lisina HCL & $\uparrow 0,03$ & $\uparrow 0,10$ \\
Carbonato cálcio & $\uparrow 0,09$ & $\uparrow 0,10$ \\
\hline
\end{tabular}

Fonte: STEIN \& LANGE (2007)

\section{DDGS na dieta de cães e gatos}

Pouca pesquisa tem sido conduzida para avaliar a eficácia de subprodutos da indústria do etanol na alimentação dos animais de companhia. Logo, a falta de dados limita a utilização desses subprodutos nas dietas para esses animais (GODOY et al., 2009).

Entre os subprodutos do milho, os DDGS e a farinha de glúten de milho possuem alta digestibilidade da matéria seca e proteína bruta para cães (YAMKA et al, 2004). Na dieta de gatos, a farinha de glúten de milho reduz o $\mathrm{pH}$ da urina, que é de importância para a saúde do trato urinário de felinos (FUNABA et al, 2005). Portanto, na indústria de alimentos para animais de estimação, a farinha de glúten de milho obtida da via úmida de produção do etanol tem sido a fonte de proteína mais utilizada. Porém, geralmente, é combinada com os produtos de soja para superar as deficiências, da farinha de glúten de milho, em aminoácidos essenciais, como lisina e triptofano (CASE et al., 2000). 
NUNES, J.K. et al. Resíduos da indústria de etanol e de biodiesel na alimentação animal. PUBVET, Londrina, V. 7, N. 18, Ed. 241, Art. 1593, Setembro, 2013.

Allen et al. (1981) realizaram quatro experimentos para avaliar o efeito de níveis de DDGS na dieta de cães. No ensaio 1 utilizaram 0, 4, 6 ou 8\% de DDGS na dieta de cães com 2 anos de idade e não observaram diferença entre os tratamentos para digestibilidade da matéria seca e do amido e nem para umidade e percentagem de matéria seca nas fezes. No ensaio 2 adicionaram 0, 8,9 ou 15,7\% de DDGS na dieta de cães da mesma idade dos do ensaio 1 e verificaram redução da digestibilidade da matéria seca e maiores teores de umidade e matéria seca nas fezes dos cães que receberam o maior percentual de DDGS. No experimento 3, na dieta de cães com 1,5 anos, adicionaram $0,13,1$ ou $26,1 \%$ de DDGS e observaram que os níveis elevados de DDGS prejudicaram a digestibilidade da matéria seca, proteína bruta e energia e atribuiram os resultados ao aumento no nível de fibra consumida e indicaram que esta diminuição na digestão não foi grave e que a inclusão de DDGS em dietas tradicionais, mesmo em níveis elevados, pode ser uma alternativa.

No ensaio 4, os mesmos pesquisadores testaram a resposta de filhotes (cães com 5 meses de idade) para um nível intermediário $(14,1 \%)$ de DDGS na dieta. Os resultados indicaram que este nível de DDGS aumentou a digestibilidade da fibra detergente ácida e diminuiu a digestibilidade da matéria seca e da energia. Logo, os cães estabelecem precocemente digestibilidade para a fibra ou possuem população bacteriana intestinal para a fermentação de fibras ou como resultado da ingestão de DDGS, o aumento do $\mathrm{pH}$ da digesta pode promover a fermentação das fibras. No mesmo experimento, os autores observaram aumento no consumo e na excreção de nitrogênio e indicaram que este aumento deve-se as diferenças no percentual de nitrogênio na ração e no consumo de ração entre os cães.

Funaba et al. (2005) avaliaram o valor nutricional do farelo de glúten de milho e da farinha de carne como fontes alimentares de proteína para gatos adultos. A digestibilidade da matéria seca foi reduzida com o farelo de glúten de milho na dieta. Todos os gatos excretaram urina alcalina $(\mathrm{pH}>7)$, mas o pH urinário e número de cristais de estruvita na urina foram menores 
NUNES, J.K. et al. Resíduos da indústria de etanol e de biodiesel na alimentação animal. PUBVET, Londrina, V. 7, N. 18, Ed. 241, Art. 1593, Setembro, 2013.

para o grupo alimentado com farinha de glúten de milho. Não houve diferença na retenção de cálcio e magnésio, entre os grupos. Do ponto de vista da digestibilidade e a utilização de $\mathrm{N}$ foi superior para farinha de glúten de milho.

\section{Conclusões}

Os ingredientes normais a serem substituídos por DDGS são milho, farelo de soja, farelo de trigo. Entretanto, é importante manter o teor de energia e aminoácidos.

A formulação da dieta para suínos contendo DDGS precisa ser baseada em teor de energia líquida e aminoácidos digestíveis.

A qualidade e a palatabilidade dos DDGS influenciam o desempenho produtivo dos animais.

A inclusão de DDGS nas dietas para suínos pode ser em, pelo menos, $20 \%$ ou inclusive superiores em alguns casos.

Existem limitações para a utilização de DDGS na dieta dos animais que são as fibras, a concentração de ácidos graxos insaturados para suínos em terminação, as micotoxinas, o percentual de aminoácidos.

A realização de mais estudos com cães e gatos.

\section{Referências}

ALLEN, S.E.; FAHEY Jr., G.C. CORBIN, J.E.; PUGH, J.L.; FRANKLIN, R.A. Evaluation of byproduct feedstuffs as dietary ingredients for dogs. Journal of Animal Science, v.53, p.1538-1544, 1981.

BATAL, A.; DALE, E.N. Mineral composition of distillers dried grains with solubles., The Journal of Applied Poultry Reserch, v.12, p.400-403, 2003.

BENZ, J.M.; LINNEEN, S.K.; DEROUCHEY, J.M.; TOKACH, M.D.; DRITZ, S.S.; NELSSEN, J.L.; GOODBAND, R.D. Effects of dried distillers grains with solubles on growth performance and fat quality of finishing pigs. Journal of Animal Science, v.85, p.105-113, 2007.

BENZ, J.M.; LINNEEN, S.K.; TOKACH, M.D.; DRITZ, S.S.; NELSSEN, J.L.; DEROUCHEY, J.M.; GOODBAND, R.D.; SULABO, R.C.; PRUSA, K.J. Effects of dried distillers grains with solubles on carcass fat quality of finishing pigs. Journal of Animal Science, v.88, p.3666-3682, 2010. 
BERGSTROM, J.R.; TOKACH, M.D.; DRITZ, S.S.; NELSSEN, J.L.; DEROUCHEY, J.M.; GOODBAND, R.D. Effects of feeder design, gender, and dietary concentration of dried distillers grains with solubles on the growth performance and carcass characteristics of growing-finishing pigs. Swine Day Report of Progress 1020, Kansas State University, Agricultural Experiment Station and Cooperative Extension Service. P 252-261, 2009.

BURKEY, T.E.; MILLER, P.S.; MORENO, R.; SHEPHERD, S.S.; CARNEY, E.E. Effects of increasing levels of distillers dried grains with solubles (DDGS) on growth performance of weanling pigs. Journal of Animal Science, 86 (Suppl. 2): 50, 2008 (Abstr.).

CASE, L.P.; CAREY, D.P.; HIRAKAWA, D.A.; DARISTOTLE, L.. Feline lower urinary tract disease. In: Canine and Feline Nutrition. Mosby Year Book Inc., St. Louis, MO. 2000, p.409428.

FASTINGER, N.D.; MAHAN, E.D.C.. Determination of the ileal amino acid and energy digestibilities of corn distillers dried grains with solubles using grower-finisher pigs. Journal of Animal Science, v.84, p.1722-1728, 2006.

FEOLI, C.; HANCOCK, J.D.; GUGLE, T.L.; CARTER, S.D. Effects of expander conditioning on the nutritional value of diets with corn-and sorghum-based distillers dried grains with solubles in nursery and finishing diets. Journal of Animal Science, 86 (Suppl. 2): 50, 2008a (Abstr).

FEOLI, C.; HANCOCK, J.D.; ISSA, S.; GUGLE, T.L.; CARTER,S.D. Effects of adding beef tallow and palm oil to diets with sorghum-based distillers dried grains with solubles on growth performance and carcass characteristics in finishing pigs. Journal of Animal Science, 86 (Suppl. 2): 52-53, 2008b. (Abstr.)

FUNABA, M.; OKA, Y.; KOBAYASHI, S.; KANEKO, M.; YAMAMOTO, H.; NAMIKAWA, K.; IRIKI, T.; HATANO, Y.; ABE, M. Evaluation of meat meal, chicken meal, and corn gluten meal as dietary sources of protein in dry cat food. Canadian Journal of Veterinary Research, v.69, p.299-304, 2005.

GODOY, M.C.R. de; BAUNER, L.L.; PARSONS, C.M.; FAHEY Jr., G.C. Select corn coproducts from the ethanol industry and their potential as ingredients in pet foods. Journal of Animal Science, v.87, p.189-199, 2009.

GREINER, L.L.; WANG, X.; ALLEE, G.; CONNOR, J.. The feeding of dry distillers grain with solubles to lactating sows. Journal of Animal Science, v.86 (Suppl. 2), p.63, 2008. (Abstr.).

HASTAD, C.W.; TOKACH, M.D.; NELSSEN, J.L.; GOODBAND, R.D.; DRITZ, S.S.; DEROUCHEY, J.M.; GROESBECK, C.N.; LAWRENCE, K.R.; LENEHAN, N.A.; KEEGAN, T.P. Energy value of dried distillers grains with solubles in swine diets. Journal of Animal Science, 82 (Suppl. 2): 50, 2004 (Abstr.).

HILL, G.M.; LINK, J.E.; LIPTRAP, O.O.; GIESEMANN, M.A.; DAWES, M.J.; SNEDEGAR, J.A.; BELLO, N.M.; TEMPELMAN, R.J. Withdrawal of distillers dried grains with solubles (DDGS) prior to slaughter in finishing pigs. Journal of Animal Science, 86 (Suppl. 2): 52, 2008 (Abstr.).

KASS, M.L.; VAN SOEST, P.J.; POND, W.G. Utilization of dietary fiber from alfalfa by growing swine. I. Apparent digestibility of diet components in specific segments of the gastrointestinal tract. Journal of Animal Science, v.50, p.175-191, 1980. 
MALLMANN, C.A.; DILKIN, P.; TYSKA, D. A importância da nutrição de precisão na produção animal. Boletim Informativo da UFSM ano3, no 3, outubro 2009, p.2-4. Disponível em: <http://jararaca.ufsm.br/websites/departamen/download/boletim_2.pdf>. Acesso em: 04 de dezembro de 2012.

NCR 1998. Nutrient Requirements of Swine. $10^{\text {th }}$ ed. National Academy Press, Washington The national Academy Press, 189p.

NOBLET, J.; PEREZ, J.M. Prediction of digestible nutrients and energy values of pig diets from chemical analysis. Journal of Animal Science, v.71, p.3389-3398, 1993.

PEDERSEN, C.; BOERSMA, M.G.; STEIN, H.H. Digestibility of energy and phosphorus in ten samples of distillers dried grains with soluble fed to growing pigs. Journal of Animal Science, v.85, p.1168-1176, 2007.

PEDERSEN, C.; PAHM, A.; STEIN, H.H. Effectiveness of in vitro procedures to estimate CP and amino acid digestibility coefficients in dried distillers grain with solubles by growing pigs. Journal of Animal Science, 83 (Suppl. 2): 39, 2005 (Abstr.).

RIBEIRO, A.M.L.; HENN, J.D.; SILVA, G.L. Alimento alternativos para suínos em crescimento e terminação. Acta Scientiae Veterinariae, v.38, p.61-71, 2010.

SPIEHS, M.J.; WHITNEY, M.H.; SHURSON, G.C. Nutrient database for distiller's dried grains with solubles produced from new ethanol plants in Minnesota and South Dakota. Journal of Animal Science, v.80, p.2639- 2645, 2002.

STEIN, H.H.; GIBSON, M.L.; PEDERSEN, C.; BOERSMA, M.G. Amino acid and energy digestibility in ten samples of distillers dried grain with solubles fed to growing pigs. Journal of Animal Science, v.84, p.853-860, 2006.

STEIN, H.; LANGE, K. 2007. Uso de DDGS na alimentação suína. Alternative feed ingredients for pigs. London Swine Conference. 2007. Disponível em: <http://www.3tres3.com.pt/buscando/uso-de-ddgs-na-alimentac\%C3\%A3o-suina_623>.

Acesso em: 30 de novembro de 2012.

STEIN, H.H.; SHURSON, G.C. Board-invited review: The use and application of distillers dried grains with solubles in swine diets. Journal of Animal Science, v.87, p.1292-1303, 2009.

SONG, M.; BAIDOO, S.K.; WHITNEY, M.H.; SHURSON, G.C.; JOHNSON, L.J. Effects of dried distillers grains with solubles on energy and nitrogen balance, and milk composition of lactating sows. Journal of Animal Science, 85 (Suppl. 2): 100-101, 2007b (Abstr.).

THACKER, P. A. Nutrient digestibility, performance and carcass traits of growing-finishing pigs fed diets containing dried wheat distillers grains with solubles. Canadian Journal of Veterinary Research, v.86, p.527-529, 2006.

VEJA, 2012. O biocombustível de maior produtividade no mundo. Disponível em: $<$ http://veja.abril.com.br/idade/exclusivo/energias_alternativas/contexto2.html>. Acesso em: 03 de dezembro de 2012.

WHITE, H.; RICHERT, B.; RADCLIFFE, S.; SCHINCKEL, A.; LATOUR, M. Distillers dried grains decreases bacon lean and increases fat iodine values (IV) and the ratio on n6:n3 but conjugated linoleic acids partially recovers fat quality. Journal of Animal Science, 85 (Suppl. 2):78, 2007 (Abstr.). 
WHITNEY, M.H.; SHURSON, G.C. Growth performance of nursery pigs fed diets containing increasing levels of corn distiller's dried grains with solubles originating from a modern Midwestern ethanol plant. Journal of Animal Science, v.82, p.122-128, 2004.

WHITNEY, M.H.; SHURSON, G.C.; JOHNSON, L.J.; WULF, D.M.; SHANKS,B.C. Growth performance and carcass characteristics of grower-finisher pigs fed high-quality corn distillers dried grain with solubles originating from a modern Midwestern ethanol plant. Journal of Animal Science, v.84:3356-3363, 2006.

WIDMER, M.R.; MCGINNIS, L.M.; WULF, D.M.; STEIN, H.H. Effects of feeding distillers dried grains with solubles, high-protein distillers dried grains, and corn germ to growing-finishing pigs on pig performance, carcass quality, and the palatability of pork. Journal of Animal Science, v.86, p.1819-1831, 2008.

WILSON, J.A.; WHITNEY, M.H.; SHURSON, G.C.; BAIDOO, S.K. Effects of adding distiller's dried grain with solubles (DDGS) to gestation and lactation diets on reproductive performance and nutrient balance. Journal of Animal Science, 81: (Suppl. 1): 110, 2003 (Abstr.).

XU, G.; BAIDOO, S.K.; JOHNSTON, L.J.; CANNON, J.E.; BIBUS, D.; SHURSON. G.C.. Effects of adding increasing levels of corn dried distillers grains with solubles (DDGS) to cornsoybean meal diets on pork fat quality of growing-finishing pigs. Journal of Animal Science, 86 (Suppl. 2): 51, 2008a (Abstr.).

YAMKA, R.M.; KITTS, S.E.; TRUE, A.D.; HARMON, L. Evaluation of maize gluten meal as a protein source in canine foods. Animal Feed Science and Technology, v.116, p.239-248, 2004. 